\title{
Short-Term Effects of Oral Administration of Pistacia Lentiscus Oil on Tissue-Specific Toxicity and Drug Metabolizing Enzymes in Mice
}

\author{
Samir Attouba Sherif M. Karam ${ }^{b}$ Abderrahim Nemmar ${ }^{c}$ Kholoud Arafat ${ }^{a}$ \\ Annie John ${ }^{d}$ Wafa Al-Dhaheri ${ }^{b}$ Mahmood Ahmed Al Sultan ${ }^{a}$ Haider Raza ${ }^{d}$ \\ ${ }^{a}$ Department of Pharmacology and Therapeutics, ${ }^{b}$ Department of Anatomy, 'Department of Physiology, \\ and ${ }^{\mathrm{d} D e p a r t m e n t}$ of Biochemistry, College of Medicine \& Health Sciences, United Arab Emirates \\ University, Al-Ain, United Arab Emirates
}

\author{
Key Words \\ Pistacia lentiscus oil • Stomach • Liver • Kidney • Blood • Cytochrome P450s
}

\begin{abstract}
Background: Pistacia lentiscus (Anacardiaceae) is a flowering plant traditionally used in the treatment of various skin, respiratory, and gastrointestinal disorders. The aim of this study was to assess whether Pistacia lentiscus oil has any short term toxic effects in vivo and in vitro. Methods: Pistacia lentiscus oil $(100 \mu \mathrm{l})$ was administered orally into mice for 5 days. Results: Measurements of body weight did not show any weight loss. Serum concentration of LDH did not show any significant statistical difference when compared to control mice. Similarly, blood, kidney or liver function tests showed no toxicity with Pistacia lentiscus oil when compared to the control group. Examination of gastrointestinal tissues sections revealed similar structural features with no difference in cell proliferation. In this context, pharmacological dilutions of Pistacia lentiscus oil $\left(10^{-6}-10^{-3}\right)$ did not affect the viability (cell death and proliferation) of mouse gastric stem cells, human colorectal cancer cells HT29, human hepatoma cells HepG2. However, it appears that at the dose and time point studied, Pistacia lentiscus oil treatment has targeted various cytochrome P450s and has specifically inhibited the activities and the expression of CYP2E1, CYP3A4, CYP1A1 and CYP1A2 differentially in different tissues. Our results also demonstrate that there is no appreciable effect of Pistacia lentiscus oil on the GSHdependent redox homoeostasis and detoxification mechanism in the tissues. Conclusion: These data suggest a good safety profile of short term oral use of Pistacia lentiscus oil as a monotherapy in the treatment of various skin, respiratory, and gastrointestinal disorders. However, due to its inhibitory effect of various cytochrome P450s and mainly CYP3A4, this might have implications on the bioavailability and metabolism of drugs taken in combination with Pistacia lentiscus oil. More attention is needed when Pistacia lentiscus oil is intended to


be uses in combination with other pharmacological agents in order to avoid potential drugdrug interaction leading to toxicity. This study will help in safer use of Pistacia lentiscus oil for therapeutic purpose.

Copyright $\odot 2014$ S. Karger AG, Basel

\section{Introduction}

Pistacia lentiscus L. (Anacardiaceae) is a flowering plant which grows in Mediterranean area. It is traditionally used in the treatment of several diseases, e.g. eczema, throat infections, diarrhea, renal stones, jaundice, asthma and gastric ulcer [1]. Mastic oil, the essential oil of mastic gum, a natural resin obtained from Pistacia lentiscus has a wide -range of therapeutic effects: anti-inflammatory, antibacterial, antifungal, antiviral, anticancer, and hypolipidemic activities [2-13]. Pistacia lentiscus is also effective in the treatment of functional dyspepsia and gastric ulcer [14-16] as well as in the healing of burns [17]. Because of its special taste, since antiquity Pistacia lentiscus has been extensively used in the Mediterranean and Middle Eastern countries as food/beverages flavouring additive and also as a traditional medicine without any reported toxicity [6]. However, a toxicological study showed that dietary treatment with mastic gum at the high dose for 13 weeks decreased body weights, and also increased liver weights [18]. In traditional medicine Pistacia lentiscus oil is used for a short period of time ( 3 to 5 days) to treat throat infections, skin rash, or functional dyspepsia. However, the safety profile of this short term use of Pistacia lentiscus has not been reported so far.

Therefore, the aim of this study was to assess in vivo the safety of Pistacia lentiscus oil after a short five days oral administration.

\section{Materials and Methods}

\section{Ethics Statement}

This project was reviewed and approved by our Institutional Review Board in compliance with College of Medicine \& Health Sciences, national and international laws and policies (EEC Council Directive 86/609, OJ L 358, 1, December 12, 1987; and NIH Guide for Care and Use of Laboratory Animals, NIH Publication No. $85-23,1985$ ) and the experiments were performed in accordance with protocols approved by the College of Medicine \& Health Sciences Animal Ethics Committee, United Arab Emirates University, Al-Ain, United Arab Emirates.

Treatment of animals with Pistacia lentiscus

Six-week-old female TO-mice (HsdOla: TO, Harlan, UK) weighing 20 to 25 g were used. Mice (five to seven in each group) were housed in 12-h light/12-h dark cycle and temperature-controlled $\left(22 \pm 1^{\circ} \mathrm{C}\right)$ room. They had free access to commercial laboratory chow and were provided with tap water ad libitum. Mice were treated by daily oral gavage of $100 \mu \mathrm{l}$ Pistacia lentiscus oil for five consecutive days. Control group received $100 \mu \mathrm{l}$ of saline solution orally. This protocol was repeated three times and the mice were monitored every day for their weight and any sign of toxicity.

Oil extraction from Pistacia lentiscus fruits

Pistacia lentiscus fruits were collected in Jijel region, Algeria and the oil was extracted from the fruits as previously reported [17]. This study was carried out on private land and the owner of the land gave permission to conduct the study on this site. Briefly, the fruits were air dried in the shade, and then oil was extracted by traditional cold-pressure in different steps. The fruits were ground into a paste, mixed for 30 mins, spread on fiber disks and then pressed. Cold water was run down the sides of the disks to increase the filtration of the oil. The liquids were then separated by decantation. At the end of this phase, Virgin Pistacia lentiscus oil was produced [17]. The chemical composition of the oil extracted from Pistacia lentiscus fruits is dominated by two monoterpene hydrocarbons: alpha-Pinene (37.9-51.5\%) and Myrcene (27-69.7\%), 
which suggest that the pharmacological effects of Pistacia lentiscus oil are mainly mediated by these two compounds [19].

\section{Chemicals and kits for toxicities}

NADH, NADPH, 1-chloro-2, 4-dinitrobenzene (CDNB), dithionitrobenzoic acid, dimethylnitrosamine (DMNA), erythromycin, 7-ethoxyresorufin, 7-methoxyresorufin, glutathione (GSH), oxidized glutathione (GSSG), glutathione reductase, cumene hydroperoxide, thiobarbituric acid and malonedialdehyde were purchased from Sigma-Aldrich Fine Chemicals (St Louis, MO, USA). 2', 7'- Dichlorofluorescein diacetate (DCFDA) and lucigenin were from Molecular Probes (Eugene, OR, USA). Polyclonal antibodies against CYP 2E1, CYP 3A4, CYP1A1 and CYP 1A2 were purchased from Amersham Int. Plc. (Amersham, UK) and $\beta$-actin from Santa Cruz Biotech (Santa Cruz, CA, USA). Reagents for SDS-PAGE and Western blot analyses were purchased from BioRad (Milwaukee, USA).

Effect of Pistacia lentiscus oil on blood, liver, and kidney functions

Blood was taken from the abdominal aorta for hematology and blood chemistry analysis. Hematological examinations were performed for the following parameters: white blood cell count (WBC), red blood cell count (RBC), hemoglobin concentration (HGB), hematocrit (HCT), platelet count, mean corpuscular volume (MCV), mean corpuscular hemoglobin (MCH), mean corpuscular hemoglobin concentration (MCHC) using an ABX VET ABC Hematology Analyzer with a mouse card (ABX Diagnostics, Montpellier, France). Serum biochemistry was performed for the following parameters: aspartate aminotransferase (AST), alanine aminotransferase (ALT), creatinine, blood urea nitrogen (BUN) and lactate dehydrogenase (LDH) using standard laboratory methods with an LX20 multiple automated analyzer (Beckman Coulter, CA, USA).

Impact of Pistacia lentiscus oil on the gastrointestinal tract cellular proliferation

To label dividing progenitor/stem cells in the $S$ phase of the cell cycle, some of the control and treated mice were injected with bromodeoxyuridine (BrdU, $120 \mathrm{mg} / \mathrm{kg}$ body weight) 1 hour before sacrifice. Three regions (stomach, small intestine and colon) of the gastrointestinal tract of control and treated mice were processed for histological examination and immunohistochemical analysis as previously mentioned [20]. The proliferative capability and location of these progenitor/stem cells in the gastrointestinal epithelium were previously characterized and well established $[20,22]$. Tissues were immediately fixed overnight in Bouin solution. Tissues were then dehydrated in ethanol, cleared in xylene and embedded in paraffin. For general morphological examination, control and treated tissue sections were stained with hematoxylin and eosin. Some sections were also probed with goat anti-BrdU antibodies. Antigen-antibody binding sites were visualized by incubating the tissue sections with peroxidase-conjugated donkey anti-goat immunoglobulin $G$ and then with diaminobenzidine.

Impact of Pistacia lentiscus oil on Cellular viability (cell death and proliferation) of gastrointestinal cell in vitro

Mouse gastric stem cells MGSC [21], human colorectal cancer cells HT29, and human hepatoma cells HepG2 were maintained in DMEM (Invitrogen, Paisley, UK). All media were supplemented with antibiotics (penicillin 50U/ml; streptomycin 50 $\mathrm{\mu g} / \mathrm{ml}$ ) (Invitrogen, Cergy Pontoise, France) and with $10 \%$ fetal bovine serum (FBS, Biowest, Nouaille, France). Cells were seeded at a density of 5,000 cells / well into 96-well plates. After $24 \mathrm{~h}$, cells were treated for another 24 and $48 \mathrm{~h}$ with different dilutions of Pistacia lentiscus oil $\left(10^{-6}-10^{-3}\right)$, in triplicate. Pistacia lentiscus oil was well dissolved in DMEM media. Control cultures were treated with $0.1 \%$ DMSO. The effect of Pistacia lentiscus oil on cell viability was determined using a CellTiterGlo Luminescent Cell Viability assay (Promega Corporation, Madison), based on quantification of ATP, which signals the presence of metabolically active cells. The luminescent signal was measured using the GLOMAX Luminometer system. Data were presented as proportional viability (\%) by comparing the treated group with the untreated cells, the viability of which is assumed to be $100 \%$.

Tissue homogenization and fractionation

Pieces of tissues obtained from liver, kidney, and brain of control and Pistacia lentiscus treated mice were rinsed with ice-cold PBS (pH 7.4) before homogenization in $10 \mathrm{mM}$ phosphate buffer $\mathrm{pH} 7.4$ containing $0.15 \mathrm{M} \mathrm{KCl}, 0.1 \mathrm{mM}$ EDTA, $1 \mathrm{mM}$ DTT and $0.1 \mathrm{mM}$ phenylmethylsulfonylfluoride at $4^{\circ} \mathrm{C}$. Postmitochondrial (PMS) fractions were prepared by centrifugation as described before [22]. 
Measurement of ROS and lipid peroxidation

ROS in different tissues of control and treated mice was measured using DCFDA as a fluorescent probe or by lucigenin based chemiluminescence methods as described before Raza et al 2004. NADPHdependent membrane lipid peroxidation was measured as thiobarbituric acid reactive substance using malonedialdehyde as a standard [22].

Measurement of GSH pool and metabolism

GSH levels and enzymes of GSH metabolism in the PMS fractions of control and treated mouse tissues were measured by standard procedures as described in previous publications [23, 24].

\section{Measurement of CYP activities}

CYP 2E1, CYP3A4, CYP1A1 and CYP1A2 activities in the tissues from control and treated mice tissues were measured using standard substrates, DMNA (for CYP 2E1), erythromycin (for CYP 3A4), 7-ethoxyresorufin (for CYP1A1) and 7-methoxyresorufin (for CYP1A2) and respectively as described previously [25] and [22].

\section{SDS-PAGE and Western blot analysis}

Proteins $(50 \mu \mathrm{g})$ from control and Pistacia lentiscus treated tissue were separated on $12 \%$ SDS-PAGE and electrophoretically transferred onto nitrocellulose paper by Western blotting using the standard procedures previously described [22]. The immunoreacting protein bands were visualized after interacting with primary antibodies against CYP 2E1, CYP3A4, CYP1A1 and CYP1A2. Beta-actin expression in each tissue was used as a loading control.

\section{Statistical analysis}

Results were expressed as means \pm S.E.M. of the number of experiments. The difference between experimental and control values were analyzed using the unpaired Student's t-test. $\mathrm{P}<0.05$ indicate a significant difference.

\section{Results}

Effect of Pistacia lentiscus oil on animal weight and hematological, kidney, and liver function tests

Five days oral treatment with Pistacia lentiscus oil $100 \mu$ l per mice doesn't show any undesirable effect on body weight or increases in LDH concentration in the serum (Fig. 1A and 1B). In addition, there were no visible abnormalities at necropsy, or any other obvious signs of toxicity. Compared to the control group, no effect of Pistacia lentiscus oil on the white blood cell count (WBC), red blood cell count (RBC), hemoglobin concentration (HGB), hematocrit (HCT), platelet count, mean corpuscular volume (MCV), mean corpuscular hemoglobin $(\mathrm{MCH})$, mean corpuscular hemoglobin concentration (MCHC) (Fig. 2A-H; p $>0.05$ ). Fig. 3 also shows the absence of statistically significant effects of Pistacia lentiscus oil on BUN, creatinine, ALT and AST activities in mice (Fig. 3A-D; $p>0.05$ ). These data suggest a good safety profile for potential human use of Pistacia lentiscus oil in short term therapy. All these experiments were repeated three times.

\section{Effect of Pistacia lentiscus oil on gastrointestinal tract cell proliferation}

Microscopic examination of control and Pistacia lentiscus treated gastrointestinal tissues (stomach, small intestine and colon) revealed similar structural features with intact lining epithelium suggesting no toxic effect for the Pistacia lentiscus oil on the structure of the gastrointestinal tract (Fig. 4A-D). Since the gastrointestinal epithelium is a highly dynamic tissue [26], it was used to test whether Pistacia lentiscus oil has any effect on cell proliferation. BrdU labeling studies revealed similar pattern of distribution of dividing cells in the three different regions examined in the gastrointestinal tract of both control and Pistacia lentiscus oil treated mice (Fig. 4A-D). 
Fig. 1. Effect of Pistacia lentiscus oil treatment on animal weight $(\mathrm{A})$, and $\mathrm{LDH}$ concentration if the serum (B). Data are mean \pm S.E.M. $(n=5$ to 7 in each group).
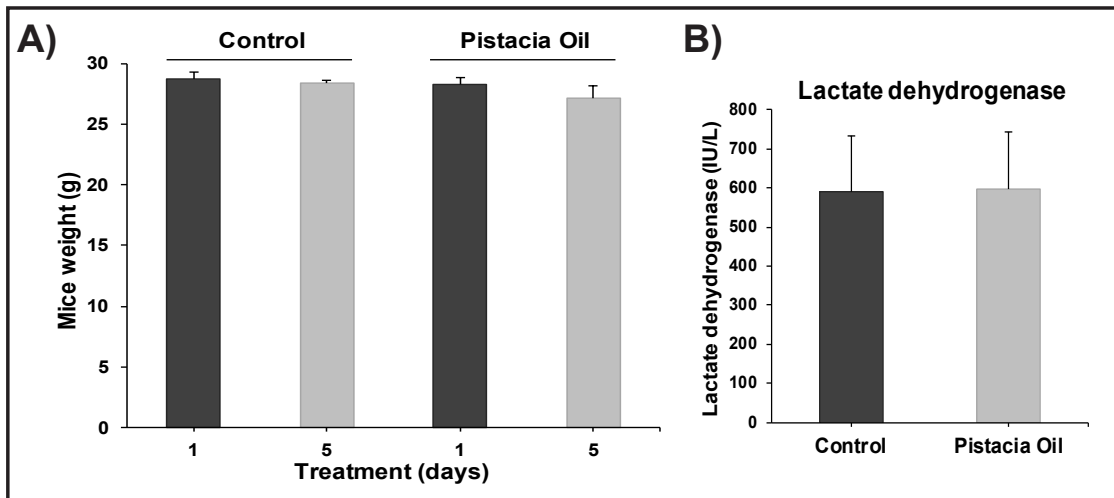

Fig. 2. Effect of Pistacia lentiscus oil treatment on the white blood cell count (WBC) (A), red blood cell count (RBC) (B), hemoglobin concentration (HGB) (C), hematocrit (HCT) (D), platelet count (E), mean corpuscular volume (MCV) (F), mean corpuscular hemoglobin (MCH) (G), mean corpuscular hemoglobin concentration (MCHC) (H). Data are mean \pm S.E.M. $(n=5$ to 7 in each group).
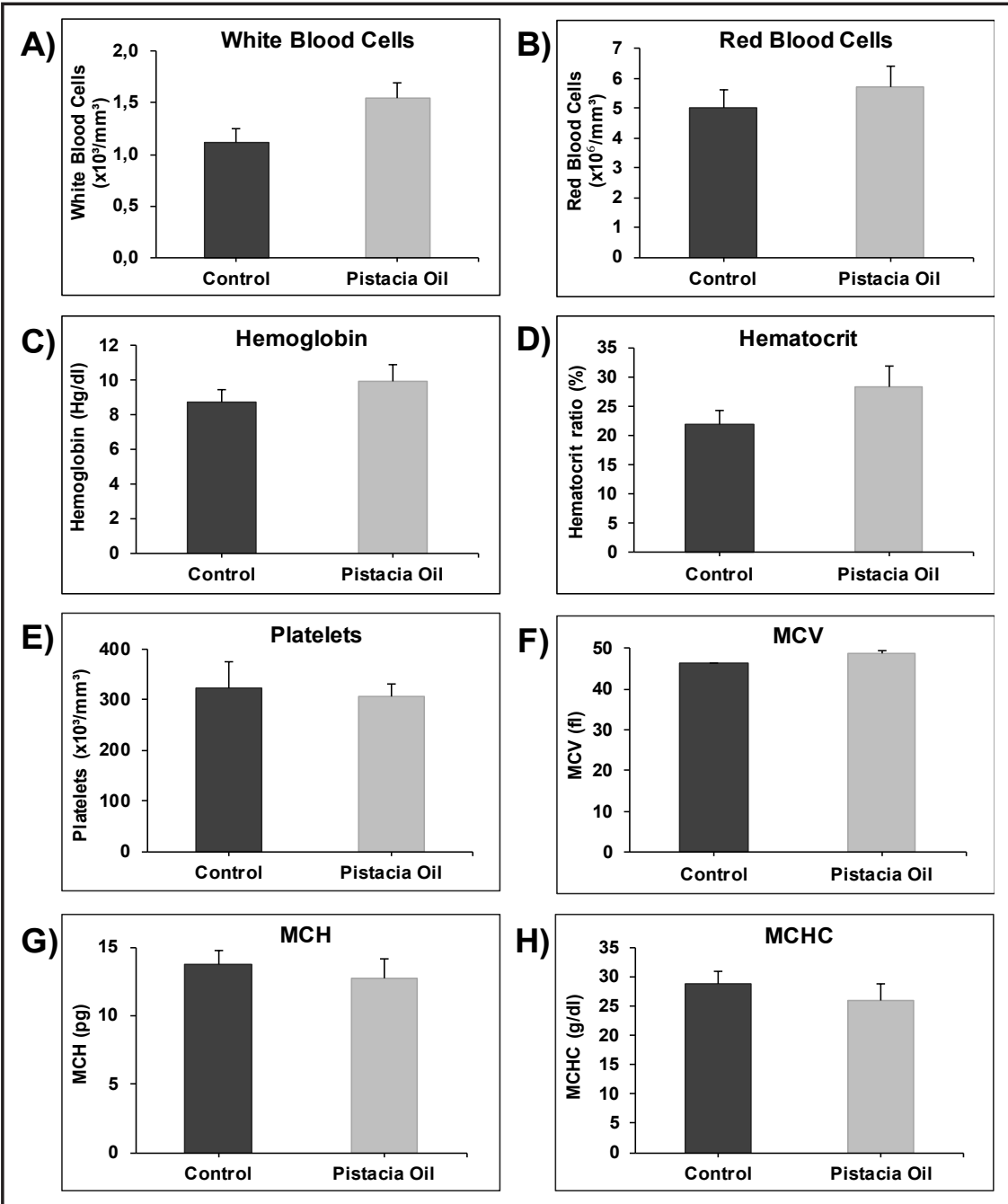

Effect of Pistacia lentiscus oil on cellular viability

To confirm in vitro the safety profile of Pistacia lentiscus oil on the mice gastrointestinal tract in vivo, we investigated the impact of Pistacia lentiscus oil on cellular viability (cell death and proliferation) of three gastrointestinal cells namely mouse gastric stem cells MGSC, human colorectal cancer cells HT29, and human hepatoma cells HepG2. As shown in Table 1 , Pistacia lentiscus oil dilutions $\left(10^{-6}-10^{-3}\right)$ doesn't have any impact on the cellular viability of MGSC, HT29, and HepG2 cells over 24 and 48 hours. All together, these data confirm the safety oral use of Pistacia lentiscus oil on the gastrointestinal tract. 
Fig. 3. Effect of Pistacia lentiscus oil treatment on BUN (A), Creatinine (B), ALT (C), and AST (D) in mice. Data are mean \pm S.E.M. $(n=5$ to 7 in each group).

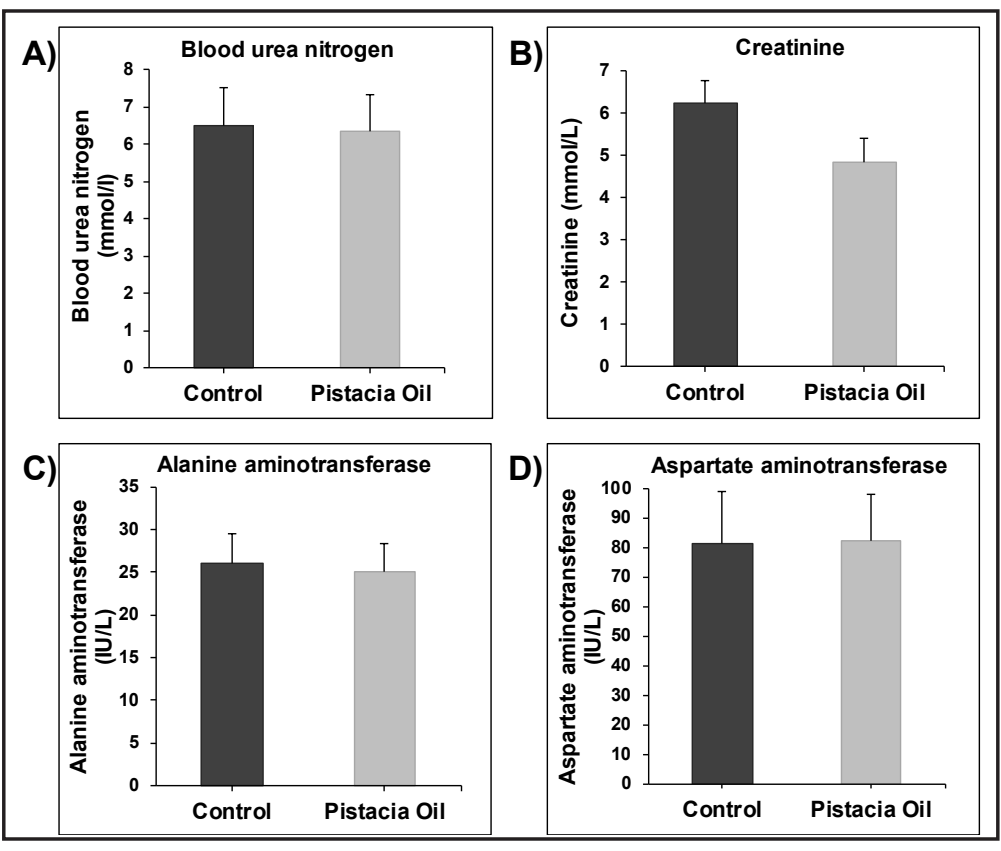

Table 1. Impact of Pistacia Ientiscus L oil on cellular viability (\% of control)

\begin{tabular}{lcccccc}
\hline Cell type & \multicolumn{2}{c}{ MGSC } & \multicolumn{2}{c}{ HT-29 } & \multicolumn{2}{c}{ HepG2 } \\
\hline $\begin{array}{l}\text { Treatment (hrs) } \\
\text { Pistacia Oil dilutions }\end{array}$ & 24 & 48 & 24 & 48 & 24 & 48 \\
$10^{-6}$ & $97 \pm 5$ & $101 \pm 1$ & $98 \pm 2$ & $93 \pm 2$ & $97 \pm 1$ & $97 \pm 1$ \\
$10^{-5}$ & $86 \pm 5$ & $99 \pm 5$ & $88 \pm 8$ & $100 \pm 5$ & $97 \pm 7$ & $92 \pm 4$ \\
$10^{-4}$ & $104 \pm 4$ & $100 \pm 2$ & $90 \pm 5$ & $110 \pm 5$ & $100 \pm 8$ & $103 \pm 4$ \\
$10^{-3}$ & $98 \pm 2$ & $88 \pm 2$ & $97 \pm 6$ & $109 \pm 6$ & $96 \pm 5$ & $108 \pm 6$ \\
\hline
\end{tabular}

Effect of Pistacia lentiscus oil on ROS and LPO

There was no significant effect of Pistacia lentiscus oil on the ROS production in the liver and kidney. On the other hand brain from Pistacia lentiscus treated mice showed a mild (20\%) increase in ROS production which was statistically significant $(\mathrm{p}<0.05)$. Similarly, there was no significant changes in the rate of membrane LPO in the tissues of Pistacia lentiscus treated mice (Table 2).

\section{Effect of Pistacia lentiscus oil on GSH metabolism}

GSH content was marginally (18\%) reduced in the liver of Pistacia lentiscus treated animals while no appreciable changes were observed in the kidneys and brain. Similarly, GST activity in the liver of Pistacia lentiscus treated mice, with CDNB as a substrate was also inhibited (25\%). On the other hand, no significant changes were observed in the kidney and brain of Pistacia lentiscus treated animals. No significant effect on GSH-Px and GSH-reductase activities in the tissues Pistacia lentiscus treated mice except GSH-Px in the liver (Table2).

\section{Effect of Pistacia lentiscus oil on CYP-dependent metabolism}

A marked inhibition (42\%) of CYP2E1 activity was observed in the liver of Pistacia lentiscus treated mice. However, this inhibition was not statistically significant $(\mathrm{p}>0.05)$. Similarly, CYP2E1 activities in the kidney and brain were not significantly affected. On the other hand, a statistically significant $40-80 \%$ decrease in the activities of CYP3A4, CYP1A1 and CYP1A2 was observed in the liver of Pistacia lentiscus treated mice $(\mathrm{p}<0.01)$. However, no significant alterations in the CYP3A4 and CYP1A1 were observed in the kidney and brain of treated animals. While CYP1A2 activity was significantly decreased in all the tissues of 


\section{Cellular Physiology and Biochemistry}

Cell Physiol Biochem 2014;33:1400-1410

\begin{tabular}{l|l}
\hline DOI: $10.1159 / 000358706$ & (c) 2014 S. Karger AG, Basel
\end{tabular}

Attoub et al.: Safety Profile of Pistacia Lentiscus Oil

Fig. 4. A) Light micrographs showing hematoxylin and eosin stained tissue sections obtained from the pyloric antrum of control (left) and treated (right) mice. The epithelial lining forms tubular units made of pits (upper arrows) and glands (lower arrows) which appeared intact in both control and treated tissues. B) Light micrographs showing BrdU-immunolabeled cells in the pyloric antrum of control (left) and treated (right) mice. A similar labeling pattern is seen in both control and treated tissues. The labeled cells have brownish nuclei and are located at the junctions between the long pits (with PAS-positive cells) and short glands. C) Light micrographs showing hematoxylin and eosin stained tissue sections obtained from the small intestine of control (left) and treated (right) mice. The epithelial lining forms large villi (arrows) and short crypts which appeared intact and more or less similar in both control and treated tissues. D) Light micrographs showing BrdU-immunolabeled cells in the colon of control (left) and treated (right) mice. A similar labeling pattern is seen in both control and treated tissues. The labeled cells have brownish nuclei and are located in the basal region of the colonic crypts. Not the PASpositive goblet cells.

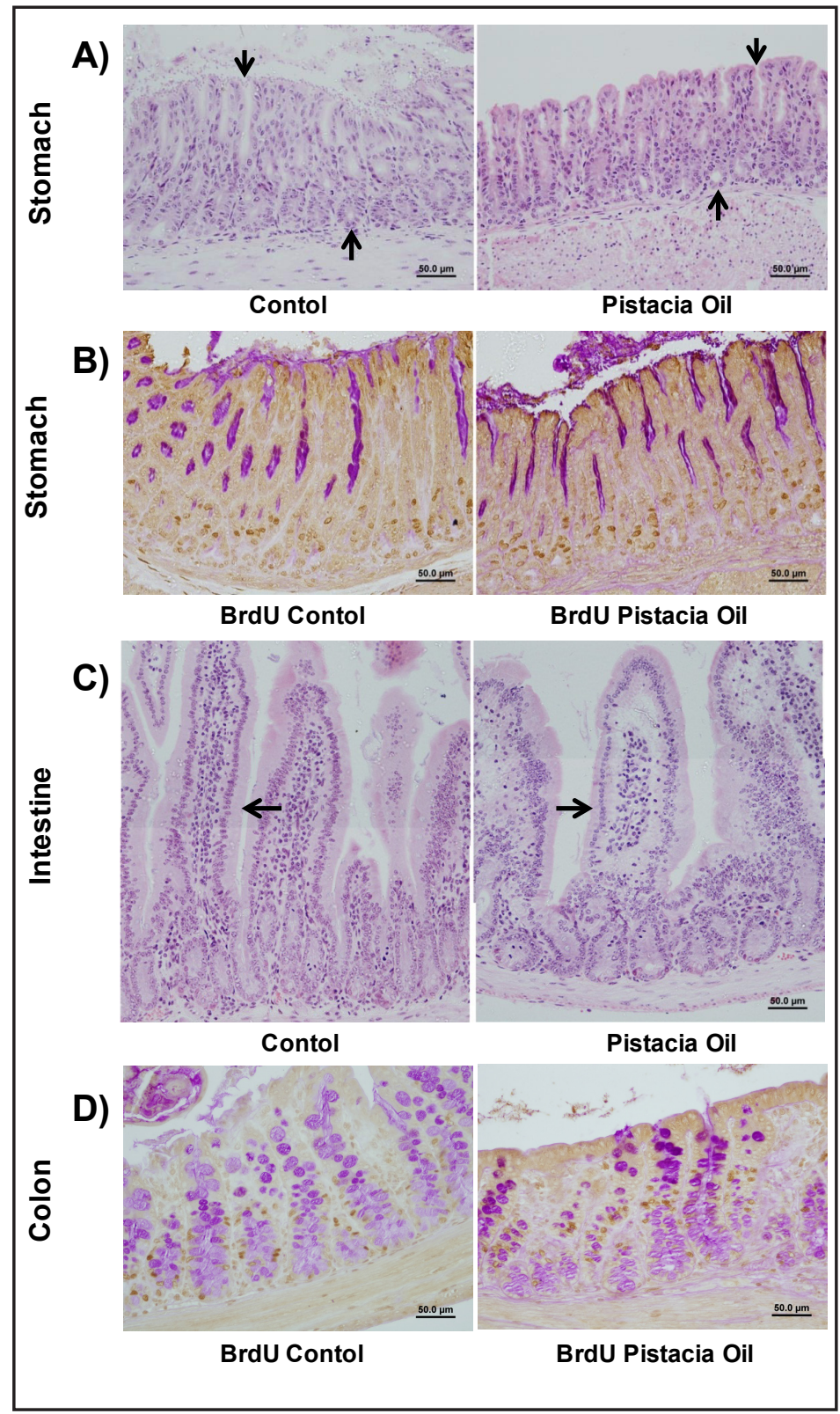

Pistacia lentiscus treated mice (Table $3 ; \mathrm{p}<0.05$ ). Western blot analysis has also confirmed the alteration in the expression of CYP2E1, CYP3A4, CYP1A1 and CYP1A2. The liver appears to be the main target for the reduced expression of key CYPs, which was in accordance with the alterations in the respective catalytic activities with their specific substrates (Fig. 5).

\section{Discussion}

Pistacia lentiscus is used as a seasoning in Mediterranean cuisine, in the production of natural chewing gum, in perfumery, in dentistry, and also for the relief of gastralgia and protection against peptic ulcer [13]. Based on the abovementioned information and since the most common of its therapeutic use has been for gastrointestinal disorders, we decided to treat the TO mice orally with $100 \mu \mathrm{l}$ Pistacia lentiscus oil for 5 consecutive days in order to investigate whether it has any toxic effects in short term treatment. In general, a $70 \mathrm{~kg}$ man has a surface area 350 times higher than a $30 \mathrm{~g}$ mouse. In traditional medicine an adult man 
Table 2. Impact of Pistacia Ientiscus L oil on post-mitochondrial supernatant (PMS) from different tissues of mice

\begin{tabular}{|c|c|c|c|c|c|c|}
\hline & \multicolumn{2}{|c|}{ Liver } & \multicolumn{2}{|c|}{ Kidney } & \multicolumn{2}{|c|}{ Brain } \\
\hline Assay & Control & Oil treated & Control & Oil treated & Control & Oil treated \\
\hline $\begin{array}{l}\mathrm{LPO} \\
\mathrm{nmol} / \mathrm{min} / \mathrm{mg} \text { prot. }\end{array}$ & $\begin{array}{l}0.0145 \pm \\
0.00\end{array}$ & $\begin{array}{c}0.017 \pm \\
0.00\end{array}$ & $\begin{array}{l}0.0274 \pm \\
0.00\end{array}$ & $\begin{array}{l}0.0269 \pm \\
0.00\end{array}$ & $\begin{array}{c}0.0534 \pm \\
0.00\end{array}$ & $\begin{array}{l}0.0448 \pm \\
0.00\end{array}$ \\
\hline $\begin{array}{l}\text { ROS } \\
\text { nmol/mg prot. }\end{array}$ & $\begin{array}{c}21.406 \pm \\
1.68\end{array}$ & $\begin{array}{c}24.390 \pm \\
1.98\end{array}$ & $\begin{array}{c}32.007 \pm \\
1.06\end{array}$ & $\begin{array}{c}32.751 \pm \\
1.10 \\
\text { ns }\end{array}$ & $\begin{array}{c}6.821 \pm \\
0.29\end{array}$ & $\begin{array}{l}\text { IS } \\
8.292 \pm \\
0.54 \\
.05\end{array}$ \\
\hline $\begin{array}{l}\text { GSH } \\
\text { nmol/mg prot. }\end{array}$ & $\begin{array}{c}45.83 \pm \\
0.79\end{array}$ & $\begin{array}{c}37.34 \pm \\
2.23\end{array}$ & $\begin{array}{c}2.29 \pm \\
0.05\end{array}$ & $\begin{array}{c}2.25 \pm \\
0.08\end{array}$ & $\begin{array}{c}5.96 \pm \\
0.22\end{array}$ & $\begin{array}{c}5.88 \pm \\
0.11 \\
\text { IS }\end{array}$ \\
\hline $\begin{array}{l}\text { GST-CDNB } \\
\mathrm{nmol} / \mathrm{min} / \mathrm{mg} \text { prot. }\end{array}$ & $\begin{array}{r}1536.43 \pm \\
26.89\end{array}$ & $\begin{array}{l}1138.48 \pm \\
45.85 \\
05\end{array}$ & $\begin{array}{c}444.83 \pm \\
21.79\end{array}$ & $\begin{array}{l}468.97 \pm \\
20.36\end{array}$ & $\begin{array}{l}344.84 \pm \\
19.12\end{array}$ & $\begin{array}{c}345.01 \pm \\
11.40\end{array}$ \\
\hline $\begin{array}{l}\text { GSH-Px } \\
\text { nmol/min/mg prot. }\end{array}$ & $\begin{array}{r}904.16 \pm \\
28.07\end{array}$ & $\begin{array}{l}824.35 \pm \\
45.28 \\
01\end{array}$ & $\begin{array}{c}684.94 \pm \\
32.33\end{array}$ & $\begin{array}{c}562.65 \pm \\
47.58 \\
\text { ns }\end{array}$ & $\begin{array}{c}36.35 \pm \\
2.28\end{array}$ & $\begin{array}{c}36.002 \pm \\
1.87 \\
\end{array}$ \\
\hline $\begin{array}{l}\text { GSSG-Reductase } \\
\mathrm{nmol} / \mathrm{min} / \mathrm{mg} \text { prot. }\end{array}$ & $\begin{array}{c}77.15 \pm \\
1.67\end{array}$ & $\begin{array}{c}68.70 \pm \\
3.56 \\
\end{array}$ & $\begin{array}{c}140.62 \pm \\
10.65\end{array}$ & $\begin{array}{c}132.49 \pm \\
8.26 \\
\text { ns }\end{array}$ & $\begin{array}{c}59.35 \pm \\
4.37\end{array}$ & $\begin{array}{c}57.86 \pm \\
1.05\end{array}$ \\
\hline
\end{tabular}

Table 3. Impact of Pistacia Ientiscus L oil on CYP 450 enzyme activities from different tissues of mice

\begin{tabular}{|c|c|c|c|c|c|c|}
\hline & \multicolumn{2}{|c|}{ Liver } & \multicolumn{2}{|c|}{ Kidney } & \multicolumn{2}{|c|}{ Brain } \\
\hline Assay & Control & Oil treated & Control & Oil treated & Control & Oil treated \\
\hline CPY 2E1 & $1402.5 \pm$ & $815.21 \pm$ & $665.12 \pm$ & $645.47 \pm$ & $692.5 \pm$ & $647.5 \pm$ \\
\hline \multirow[t]{2}{*}{ pmol/mg prot. } & 50.60 & 52.01 & 39.46 & 21.27 & 6.79 & 10.77 \\
\hline & \multicolumn{2}{|c|}{ ns } & \multicolumn{2}{|c|}{ ns } & \multicolumn{2}{|c|}{ ns } \\
\hline \multirow{2}{*}{$\begin{array}{l}\text { CPY3A4 } \\
\text { pmol/mg prot. }\end{array}$} & $1317.5 \pm$ & $880.54 \pm$ & $543.81 \pm$ & $540.25 \pm$ & $523.17 \pm$ & $562.89 \pm$ \\
\hline & \multicolumn{2}{|c|}{$\mathrm{P}<0.01$} & \multicolumn{2}{|c|}{ ns } & \multicolumn{2}{|c|}{ ns } \\
\hline CPY1A1 & $1560.11 \pm$ & $378.81 \pm$ & $37.44 \pm$ & $35.44 \pm$ & $39.33 \pm$ & $35.21 \pm$ \\
\hline \multirow[t]{2}{*}{ pmol/mg prot. } & 31.31 & 15.82 & 1.60 & 2.59 & 0.98 & 2.32 \\
\hline & \multicolumn{2}{|c|}{$\mathrm{P}<0.001$} & \multicolumn{2}{|c|}{ ns } & \multicolumn{2}{|c|}{ ns } \\
\hline CPY1A2 & $1681.41 \pm$ & $493 \pm$ & $113.80 \pm$ & $82.71 \pm$ & $51.79 \pm$ & $32.41 \pm$ \\
\hline \multirow[t]{2}{*}{ pmol/mg prot. } & 24.59 & 8.25 & 7.90 & 1.78 & 3.57 & 0.87 \\
\hline & \multicolumn{2}{|c|}{$\mathrm{P}<0.001$} & \multicolumn{2}{|c|}{$\mathrm{P}<0.05$} & \multicolumn{2}{|c|}{$\mathrm{P}<0.05$} \\
\hline
\end{tabular}

will be using $10 \mathrm{ml}$ of Pistacia lentiscus once to twice a day for 3 to 5 days. Then, the $100 \mu \mathrm{l}$ Pistacia lentiscus oil used in mice is a little higher than the $10 \mathrm{ml}$ of Pistacia lentiscus used once to twice a day in traditional medicine.

A chronic toxicological study showed that dietary treatment with mastic gum for 13 weeks decreased body weights at the high dose, and also increased liver weights [18]. A more recent study demonstrates a promotion potential of mastic on the formation of preneoplastic lesions in the established rat liver medium-term carcinogenesis bioassay [27]. On the contrary, our dietary treatment with Pistacia lentiscus oil for 5 days shows an extremely 
Fig. 5. $50 \mu \mathrm{g}$ of proteins from control (C) and Pistacia lentiscus oil treated ( $\mathrm{T}$ ) tissues (liver, kidney and brain) were separated on $12 \%$ SDS-PAGE. The proteins were transferred to nitrocellulose membrane by Western blotting and immunoreactive bands were visualized by reacting with antibodies against CYP2E1, CYP3A4, CYP1A1 and CYP1A2. Beta-actin was used as a loading control. R.I values indicate relative intensity of the protein band (as determined by gel densitometer from Vilber Lormat, France) using expression of the proteins in the control tissues as 1.0. A typical blot from three repeated experiments is shown.

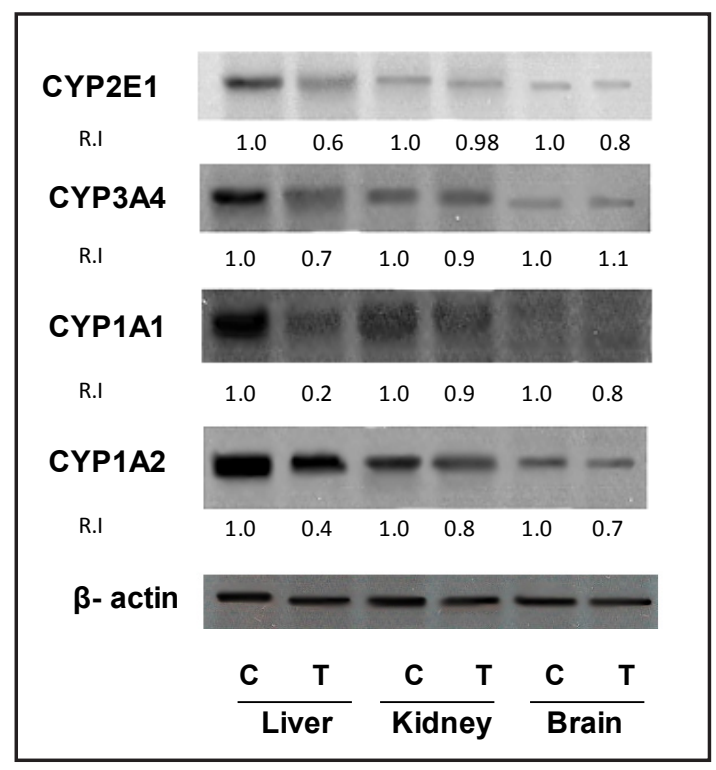

safe profile on animal weight, as well as on the most direct target toxicity organs blood, kidney and liver. Effectively, no increases in serum concentration of LDH was observed after treatment with Pistacia lentiscus oil which is in line with previously published report in vitro indicating no leakage of the cytosolic enzyme LDH into the extracellular space after treatment with Pistacia lentiscus oil [28]. No damage of the gastrointestinal mucosa or alteration in cell proliferation was observed which is in line with the capacity of Pistacia lentiscus oil to eradicate Helicobacter pylori and treat gastro-duodenal ulcer $[14,16]$. These results have shown that the Pistacia lentiscus oil contents have little effects on the GSH-dependent redox metabolism in treated mice for this period and dose. However, it appears that at this dose and time point, Pistacia lentiscus oil treatment has inhibited the expression and the activities of CYP2E1, CYP3A4, CYP1A1 and CYP1A2. P450-isoenzymes, CYP 3A4, CYP 1A2 and CYP 2E1, are abundant in the mouse liver, and found to be the main target of Pistacia lentiscus oil treatment. The majority of the pharmacologically active compounds and xenobiotics have been reported to be metabolized, including in humans, by CYP 3A4, CYP 1A2 and CYP 2E1, and therefore the inhibition of these CYPs by Pistacia lentiscus oil might have implications in drug metabolizing ability of individuals taking the Pistacia lentiscus oil as a treatment along with other drugs. However, when used as monotherapy, Pistacia lentiscus oil is expected to be a safe drug as demonstrated cross this study. It is, however, not clear from this study whether any specific component of the Pistacia lentiscus oil or their metabolites is effective in targeting the CYP isoenzymes in different tissues. Differential effects of oil treatment on the expression and activities of various CYPs in different tissues might also be associated with the different degree of bioavailability and metabolism of the active components present in the Pistacia lentiscus oil. Further studies are needed to identify the active compound (s) which is selectively inhibiting the CYP isoenzymes in different tissues. Future studies are also planned to elucidate the mechanism of CYP inhibition at the mRNA/protein expression level. In addition, we also planned to study the kinetics of the inhibition of CYP activity by Pistacia lentiscus oil under in vitro and in vivo conditions.

Therefore, treatment or usage of this Pistacia lentiscus oil should be recommended with cautions as metabolism of drugs in general may be affected by inhibition of different P450s in tissues and especially in the liver which is the main target of drug metabolism. In addition, our results also demonstrate that GSH-dependent phase 2 conjugation reaction and detoxification of drugs, on the other hand may not be affected significantly by the Pistacia lentiscus oil treatment. There appears to be no significant effect on the oxidative stress as both, ROS production and membrane lipid peroxidation in the tissues were not appreciably and consistently affected by the Pistacia lentiscus oil treatment. Our results, especially 
targeted effects on CYP activities are significant in determining the efficacy of prodrugs which require metabolic activation for their pharmacological effects. This study may also have implications on activation and inactivation of pro-carcinogen/carcinogens (polycyclic aromatic hydrocarbon "PAH", benzo (a) pyrene "BP", cigarette smoke, etc.) in biological systems when treated with this edible oil. The anti-carcinogenic effect of Pistacia lentiscus oil may be associated with its inhibitory effect on carcinogen activation by CYP $1 \mathrm{~A} 1 / 1 \mathrm{~A} 2$. On the contrary, it has been reported that Chios Mastic Gum has a potential on the formation of preneoplastic lesions in the established rat liver medium-term carcinogenesis bioassay [27].

\section{Conclusions}

Pistacia lentiscus oil treatment has inhibited specific CYP isoenzymes expression and catalytic activities as determined by using isoenzyme-specific substrates and antibodies. However, this effect on the key CYPs seems to be tissue- and isoenzyme-specific and further studies in progress will elucidate the mechanism of the inhibition of CYP activities in Pistacia lentiscus oil treated animals. Pistacia lentiscus oil treatment orally, however, does not seem to induce any acute tissue specific toxicity as shown by analyzing the stable markers and histochemistry of the target tissue. Also, the overall redox homeostasis and GSH-dependent detoxification mechanism in the tissues remained more or less unaltered after the Pistacia lentiscus oil treatment. Pistacia lentiscus oil can be safely used in monotherapy. However, due to its inhibitory effect on both the activities and the expression of various CYPs, careful attention is need when Pistacia lentiscus oil is intended to be combined with other drugs due to potential drug-drug interaction leading to toxicity. This study will help in safer use of Pistacia lentiscus oil for therapeutic purpose.

\section{Acknowledgement}

The authors wish to thank Ms. Shaheen Zia from Department of Physiology FMHS for her excellent technical help. The work is supported by Terry Fox Cancer Research funds and funds from the Research Committee, CMHS, UAE University.

\section{References}

1 Duru ME, Cakir A, Kordali S, Zengin H, Harmandar M, Izumi S, Hirata T: Chemical composition and antifungal properties of essential oils of three pistacia species. Fitoterapia 2003;74:170-176.

2 Marone P, Bono L, Leone E, Bona S, Carretto E, Perversi L: Bactericidal activity of pistacia lentiscus mastic gum against helicobacter pylori. J Chemother 2001;13:611-614.

-3 Koutsoudaki C, Krsek M, Rodger A: Chemical composition and antibacterial activity of the essential oil and the gum of pistacia lentiscus var. Chia. J Agric Food Chem 2005;53:7681-7685.

-4 Loutrari H, Magkouta S, Pyriochou A, Koika V, Kolisis FN, Papapetropoulos A, Roussos C: Mastic oil from pistacia lentiscus var. Chia inhibits growth and survival of human k562 leukemia cells and attenuates angiogenesis. Nutr Cancer 2006;55:86-93.

5 Balan KV, Prince J, Han Z, Dimas K, Cladaras M, Wyche JH, Sitaras NM, Pantazis P: Antiproliferative activity and induction of apoptosis in human colon cancer cells treated in vitro with constituents of a product derived from pistacia lentiscus l. Var. Chia. Phytomedicine 2007;14:263-272.

-6 Moulos P, Papadodima O, Chatziioannou A, Loutrari H, Roussos C, Kolisis FN: A transcriptomic computational analysis of mastic oil-treated lewis lung carcinomas reveals molecular mechanisms targeting tumor cell growth and survival. BMC Med Genomics 2009;2:68. 


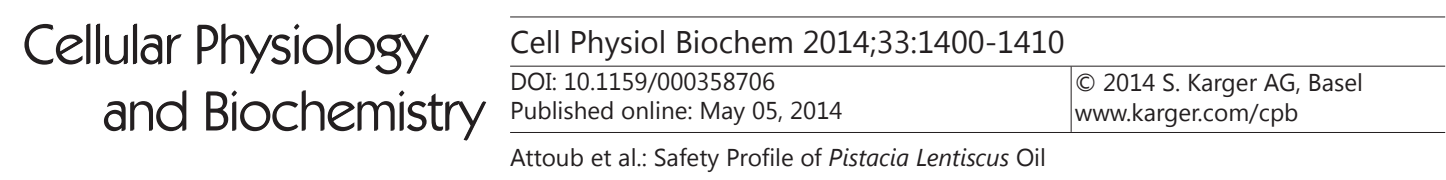

7 Zhou L, Satoh K, Takahashi K, Watanabe S, Nakamura W, Maki J, Hatano H, Takekawa F, Shimada C, Sakagami H: Re-evaluation of anti-inflammatory activity of mastic using activated macrophages. In Vivo 2009;23:583-589.

8 Magkouta S, Stathopoulos GT, Psallidas I, Papapetropoulos A, Kolisis FN, Roussos C, Loutrari H: Protective effects of mastic oil from pistacia lentiscus variation chia against experimental growth of lewis lung carcinoma. Nutr Cancer 2009;61:640-648.

-9 Mahmoudi M, Ebrahimzadeh MA, Nabavi SF, Hafezi S, Nabavi SM, Eslami S: Antiinflammatory and antioxidant activities of gum mastic. Eur Rev Med Pharmacol Sci 2010;14:765-769.

10 Triantafyllou A, Bikineyeva A, Dikalova A, Nazarewicz R, Lerakis S, Dikalov S: Anti-inflammatory activity of chios mastic gum is associated with inhibition of tnf-alpha induced oxidative stress. Nutr J 2011;10:64.

11 Qiao J, Li A, Jin X, Wang J: Mastic alleviates allergic inflammation in asthmatic model mice by inhibiting recruitment of eosinophils. Am J Respir Cell Mol Biol 2011;45:95-100.

12 Maxia A, Sanna C, Frau MA, Piras A, Karchuli MS, Kasture V: Anti-inflammatory activity of pistacia lentiscus essential oil: Involvement of il-6 and tnf-alpha. Nat Prod Commun 2011;6:1543-1544.

13 Paraschos S, Mitakou S, Skaltsounis AL: Chios gum mastic: A review of its biological activities. Curr Med Chem 2012;19:2292-2302.

14 Huwez FU, Thirlwell D, Cockayne A, Ala'Aldeen DA: Mastic gum kills helicobacter pylori. N Engl J Med 1998;339:1946.

15 Dabos KJ, Sfika E, Vlatta LJ, Frantzi D, Amygdalos GI, Giannikopoulos G: Is chios mastic gum effective in the treatment of functional dyspepsia? A prospective randomised double-blind placebo controlled trial. J Ethnopharmacol 2010;127:205-209.

16 Dabos KJ, Sfika E, Vlatta LJ, Giannikopoulos G: The effect of mastic gum on helicobacter pylori: A randomized pilot study. Phytomedicine 2010;17:296-299.

17 Djerrou Z, Maameri Z, Hamdi-Pacha Y, Serakta M, Riachi F, Djaalab H, Boukeloua A: Effect of virgin fatty oil of pistacia lentiscus on experimental burn wound's healing in rabbits. Afr J Tradit Complement Altern Med 2010;7:258-263.

18 Kang JS, Wanibuchi H, Salim EI, Kinoshita A, Fukushima S: Evaluation of the toxicity of mastic gum with 13 weeks dietary administration to f344 rats. Food Chem Toxicol 2007;45:494-501.

19 Mecherara-Idjeri a S, Hassani A, Castola V, Casanova J: Composition and Chemical Variability of the Essential Oil from Pistacia lentiscus L. Growing Wild in Algeria. J. Essent. Oil Res 2008;20:32-38.

20 Karam SM, John R, Alpers DH, Ponery AS: Retinoic acid stimulates the dynamics of mouse gastric epithelial progenitors. Stem Cells 2005;23:433-441.

21 Farook VS, Alkhalaf M, Karam SM: Establishment of a gastric epithelial progenitor cell line from a transgenic mouse expressing the simian virus 40 large $t$ antigen gene in the parietal cell lineage. Cell Prolif 2008;41:310-320.

22 Raza H, Prabu SK, Robin MA, Avadhani NG: Elevated mitochondrial cytochrome p450 2e1 and glutathione s-transferase a4-4 in streptozotocin-induced diabetic rats: Tissue-specific variations and roles in oxidative stress. Diabetes 2004;53:185-194.

-23 Raza H, John A: Glutathione metabolism and oxidative stress in neonatal rat tissues from streptozotocininduced diabetic mothers. Diabetes Metab Res Rev 2004;20:72-78.

24 Raza H, John A: In vitro effects of tea polyphenols on redox metabolism, oxidative stress, and apoptosis in pc12 cells. Ann N Y Acad Sci 2008;1138:358-365.

25 Bhagwat SV, Mullick J, Raza H, Avadhani NG: Constitutive and inducible cytochromes p450 in rat lung mitochondria: Xenobiotic induction, relative abundance, and catalytic properties. Toxicol Appl Pharmacol 1999;156:231-240.

-26 Karam SM: Lineage commitment and maturation of epithelial cells in the gut. Front Biosci 1999;4:D286298.

27 Doi K, Wei M, Kitano M, Uematsu N, Inoue M, Wanibuchi H: Enhancement of preneoplastic lesion yield by chios mastic gum in a rat liver medium-term carcinogenesis bioassay. Toxicol Appl Pharmacol 2009;234:135-142.

28 Ljubuncic P, Portnaya I, Cogan U, Azaizeh H, Bomzon A: Antioxidant activity of crataegus aronia aqueous extract used in traditional arab medicine in israel. J Ethnopharmacol 2005;101:153-161. 